\title{
Rigoberta Menchú: el nombre no es un destino
}

Rigoberta Menchú: name is not a destiny

\section{NURIA GIRONA FIBLA}

UNIVERSITAT DE VALÈNCIA · nuria.girona@uv.es

Profesora de Literatura latinaomericana en la Universitat de València. Directora del proyecto de investigación 'Cultura y movimientos sociales' y autora de los libros Escrituras de la historia. La novela argentina de los años 80 (1995), El lenguaje es una piel (1995), Rituales de la verdad. Mujeres y discursos en América Latina (2010).

\section{Gema PaLAZÓn SÁEZ}

UNIVERSITÉ LILLE III · gemapalazon@gmail.com

Realiza su tesis doctoral sobre los testimonios de la revolución sandinista, ha publicado diferentes artículos sobre el tema y el libro Memoria y escrituras de Nicaragua. Cultura y discurso testimonial en la Revolución Sandinista (2010).

Resumen: De emblema del circuito académico al de la nación guatemalteca, de la internacionalización de su labor pacifista a la circulación global, de la solidaridad subalterna al fetichismo de la mercancía, Menchú ha encarnado tanto un objeto de deseo como un objeto de disputa y con ello ha dejado al descubierto las aristas entre lo dominante y lo subalterno, lo central y lo periférico, lo ideológico y lo estético, lo alegórico y lo institucional. En definitiva, ha abierto un espacio de tensiones y choques en las dinámicas de resistencia cultural que oponen las identidades no hegemónicas a los códigos opresores, las relaciones entre el poder metropolitano-occidental y el saber académico, la reconversión de lo popular y lo nacional bajo el efecto globalizador de las industrias culturales.

Palabras clave: Rigoberta Menchú, Testimonio, Suablternidad.
Resumen: This paper deals with the changing role of Rigoberta Menchú in the debates and cultural fights on subalternity, empowerment and hegemony in Latin America. The authors analyze the changing positions in Menchú's discourses and in the social and cultural representations of her as a cultural icon.

Palabras clave: Rigoberta Menchú, Testimony, Suablternity. 
Por mi parte, he conseguido un empleo, he subido de clase y decido quiénes hablan o lo que dicen cuando los dejo hablar. ¿Puede ser que sea eso lo que yo hago con Rigoberta Menchú, que la esté usando como trataron de hacerlo Elisabeth Burgos o John Berverley y muchos de nosotros, los intelectuales, para decir lo que nosotros queremos decir?

Marc Zimmerman

Ya ha pasado mucho tiempo desde aquella tarde lluviosa y fría de 1982 en la que, según cuenta Elizabeth Burgos, Rigoberta Menchú llegó a su casa de París: "no llevaba medias ni abrigo. Sus brazos asomaban desnudos de su huipil (...). Su mirada franca era la de un niño, con labios siempre dispuestos a sonreír" (Burgos, 1997: 12).

La misma Rigoberta Menchú, "una muchacha indígena muy interesante” según Arturo Taracena, a quien acompañó a casa de Burgos una tarde y al día siguiente muy temprano, ya que ella no podía acudir allí por sus propios medios: "eso era imposible: Rigoberta no hablaba francés, no sabía manejarse en el metro, pues era la primera vez que estaba en París” (Taracena, 1999: 130). El propósito inicial de este encuentro -y en esto sí coinciden los informantes- se limitaba a una entrevista, aunque Taracena no desveló su colaboración hasta dieciséis años después ${ }^{1}$.

El tiempo transcurrido ha abierto una brecha que va más allá de las divergencias entre estos relatos o de lo que hoy conocemos de su protagonista. Una distancia insalvable parece haberse impuesto entre las circunstancias de este encuentro, del que surgió Me llamó Rigoberta Menchú y así me nació la conciencia, y las repercusiones que alcanzaría; entre la Rigoberta Menchú que emergió de su primera textualización y los vuelos de su trayectoria literaria y política -mal calculada, quizás, según se desprende de la ingenua presentación de estos relatos-; entre el espacio de negociación que este libro abría en relación al estatuto del subalterno y la representación de la dirigente indígena al respecto.

Las discrepancias entre estas versiones no pasarían de ciertas inexactitudes factuales, que bien podrían atribuirse a licencias literarias o a detalles irrelevantes en el propósito del libro, si no fuera porque, desde el comienzo, asediaron su publicación. A las controversias sobre la medida de los hechos relatados por Menchú (las fuentes de su información, las omisiones voluntarias e involuntarias, la veracidad de los sucesos expuestos) se sumaron los originados acerca de la composición del libro (desde cómo se ideó la recopilación del material para la entrevista hasta la autoría de su transcripción o la impronta de Elizabeth Burgos en el diseño final de la obra). Precisiones y cuestionamientos que pudieron quedar ahí de no prestarse a revisiones críticas sobre el estatuto del testimonio en sus distintas

\footnotetext{
1Para más información sobre los aspectos relativos a los primeros encuentros entre Elizabeth Burgos, Rigoberta Menchú y Arturo Taracena pueden consultarse la entrevista de Luis Aceituno (1999) y el recuento que Arturo Arias (2001a) ha hecho de los mismos.
} 
modalidades, a la reflexión sobre la función del intelectual letrado, a la redefinición de las fronteras disciplinarias o a la constitución de un objeto de estudio privilegiado por los departamentos de Estudios Culturales y el Grupo Latinoamericano de Estudios Subalternos.

Lo cierto es que, lo que se apuntaba como un desajuste de versiones, no sólo sembró discusiones y una ingente bibliografía ${ }^{2}$, sino que operó como una división de los campos críticos y obligó a una rearticulación de los mapas culturales en América Latina; su alcance derivó precipitadamente en polémicas políticas (relativas a la orientación curricular universitaria en Estados Unidos) e, incluso, en delaciones sobre la supremacía de la red que convocaba este debate postcolonial. Por si fuera poco, en ocasiones los desencuentros descendieron a cruces de acusaciones particulares, donde "lo personal" mostró un oscuro lado político y las pugnas narcisistas del mundo académico -siempre presentesirrumpieron con una visibilidad inaudita y con un nivel cercano al chismorreo ${ }^{3}$. Hasta ese dique de contención levantó la querella alrededor de Rigoberta Menchú ${ }^{4}$.

En el fragor de esta batalla, su figura transitó a medio camino entre el liderazgo y la instrumentalización, el icono y el consumo cultural, la resignificación y el vaciamiento de su nombre. Por momentos, ciertas apostillas se desenvolvían ajenas a sus acciones y su persona (sobre Rigoberta pero sin Rigoberta y no precisamente por su imposibilidad de hablar); al mismo tiempo, otras acotaciones surtían orquestadas por su voluntad o promovidas expresamente por sus intervenciones públicas, mientras

2 A la enorme cantidad de artículos y estudios sobre el tema hay que sumar, entre otros, los trabajos recopilatorios de Arturo Arias $(2001 b, 2001 c)$, que trató de sintetizar de forma global y plural la controversia alrededor de Me llamo Rigoberta Menchú y así me nació la conciencia, y Mario Roberto Morales (2001). Del mismo modo, Marc Zimmerman (1999, 2001, 2006), Mary Louis Pratt (1999) o John Beverley $(1999,2002)$ han tratado de abordar la cuestión desde una perspectiva que diera cuenta del contexto en que surgieron las polémicas, de su incidencia en el campo crítico o de su participación personal en el debate.

${ }^{3}$ La disputa ha persistido hasta nuestros días en forma de ataques personales entre distintos intelectuales que se mueven o bien en el desprestigio del trabajo de D. Stoll, o bien en la teoría de una conspiración de intelectuales de izquierda que censuran, niegan y acosan a aquellos que no comparten su visión del testimonio de Menchú. Roberto Morales (2003), J. Beverley (2004a), M. Zimmerman (2004), A. Arias (2004) y D. Stoll (2002 [1999]) han revisado en distintas publicaciones estos enfrentamientos que se sitúan, la mayoría de las veces, lejos de la problemática alrededor de la crisis de representación del testimonio. También el texto con el que Elizabeth Burgos prologó la reedición del libro de David Stoll (Rigoberta Menchú and the story of all poor Guatemalans, 2008) constata el peso que algunas de estas recriminaciones y enfrentamientos siguen teniendo en el ámbito de la crítica estadounidense, como se verá más adelante.

${ }^{4}$ Por supuesto, ella misma tampoco se libró de esas maledicencias. Sólo por citar un ejemplo, algunos críticos reaccionaron con cierto descontento a la noticia de su boda en 1996, ya que contradecía sus declaraciones en Me llamo Rigoberta Menchú... Marc Zimmerman alude a esta cuestión al afirmar: “El año 1996 no fue muy bueno para Rigoberta en relación a todo lo que muchos de nosotros habíamos intentado hacer con su historia y su nombre [...] Rigoberta Menchú superó sus dudas y decepcionó a algunos de sus aficionados por el hecho de casarse" (Zimmerman, 1999, 516). Anécdotas como esta establecen una relación directa entre el testimonio de Menchú y su proyección pública, hasta el punto de cuestionar incluso decisiones de carácter privado: persona y personaje se tornan así indisociables para el ámbito de la crítica. 
recogía premios o impartía conferencias, ataviada con su huipil -como un souvernir maya-quiché-, no podía ser de otra manera y así se esperaba que fuera ${ }^{5}$.

Cuando se agotó como sujeto subalterno, Rigoberta Menchú supo valerse del tirón “mediático” o “de interés" para seguir difundiendo sus ideas en recintos universitarios, ser embajadora de la ONU o presentarse a las elecciones presidenciales desde su propia formación política. Por entonces, "Rigoberta Menchú" había trascendido su individualidad y su propia representatividad étnica -hasta la necesidad académica de comprender la alteridad- y el personaje histórico había sido subsumido por un cascarón simbólico sumamente apto, en su abstracción local, a la nueva universalidad del capitalismo transnacionalizado.

De emblema del circuito académico al de la nación guatemalteca, de la internacionalización de su labor pacifista a la circulación global, de la solidaridad subalterna al fetichismo de la mercancía, Menchú ha encarnado tanto un objeto de deseo como un objeto de disputa y con ello ha dejado al descubierto las aristas entre lo dominante y lo subalterno, lo central y lo periférico, lo ideológico y lo estético, lo alegórico y lo institucional. En definitiva, ha abierto un espacio de tensiones y choques en las dinámicas de resistencia cultural que oponen las identidades no hegemónicas a los códigos opresores, las relaciones entre el poder metropolitano-occidental y el saber académico, la reconversión de lo popular y lo nacional bajo el efecto globalizador de las industrias culturales.

Han pasado más de treinta años desde la publicación de Me llamo Rigoberta Menchú y asíme nació la conciencia, la crítica ha cambiado sus lugares de enunciación tanto como se ha transformado la trayectoria pública y política de su protagonista dentro y fuera de Guatemala. Más allá de las verdades y mentiras, los secretos y su publicitación, del Premio Nobel o de su campaña presidencial o quizá debido a todo lo anterior, quizás sea el momento de interrogarse sobre la intensa productividad simbólica a la que ha dado lugar y retomar sus encuentros y desencuentros, no con ánimo de síntesis ni compilación, ni siquiera de rectificación, sino más bien para articular las apropiaciones sobre su figura, los usos -a veces, abusos y pretextos- que a partir de ella o desde ella misma, con ella o sin ella, por ella o contra ella se han generado.

Exponer estas pugnas implica reproducir inevitablemente sus detalles, aunque nuestro objetivo sólo persiga señalar sus desvíos, mostrar su inoperancia, leer en otra dirección sus aportaciones para descubrir hasta qué punto los desajustes con los que inicialmente se acusó a Menchú cobrarían una

\footnotetext{
5 "La condición de Rigoberta como víctima puede que sea una desgracia para su felicidad personal, pero es indispensable para su reputación académica [...] Su propia apariencia y vestimenta indígena constituyen un reproche a la cultura europea; de arreglarse el pelo o ponerse un traje Rigoberta se corrompería con las baratijas de la cultura occidental" (D'Souza, 1991: $72-73)$.
} 
dimensión insospechada en la actualidad, al apuntar núcleos certeros pero equivocar sus razonamientos (despistados, gratuitos o ponzoñosos).

Lo que el tiempo no parece haber resuelto es la fricción que ocasiona la consideración de esta figura como objeto (de saber, como informante, como paradigma) y como sujeto (de su historia, de su vida, de su imagen). En esta ambigua y porosa dualidad se modulan buena parte de las antiguas y nuevas polémicas.

No está en juego, por lo tanto, "la verdad" de su testimonio sino los usos de esa verdad, o mejor aún, cómo y quién se autoriza a utilizarla en las dos direcciones que el "clásico" binomio entre intelectual solidario/sujeto subalterno instauraba. Pareciera que como objeto, su propio personaje le imprimía un destino que ella se ha encargado de modificar para asombro, desengaño o regocijo de seguidores y detractores. No cabe duda de que mediante el proyecto editorial de Burgos, Menchú accedió a su propia puesta en escena en el espinoso filo testimonial de la persona y el personaje, de la voz y la letra, del compromiso y la venta. El espacio cedido en esta mediación, a la par que la fijaba literariamente (en tanto le adjudicaba un tono y un retrato) le abría posibilidades para su propia “actuación” (intervención, difusión, práctica y provecho). Lo que entonces podía leerse como un producto discursivo de cuidada manufactura se reveló más como un proceso inconcluso que adquiría vida propia, perdiendo de vista que en la medida en que quedó armada se construía performativamente, que su representación también contenía una autorrepresentación.

Es ahora cuando se percibe que la disyuntiva que esta obra desplegó no se resolvía mediante una indagación detectivesca, sino en los equívocos de una historia que la convertía en objeto a la par que la excluía como sujeto de la suya propia e, incluso, de la posibilidad de un proyecto en solitario. Los problemas no han surgido -según cierta perspectiva postcolonial se encargó de dilucidar al principio- de la falacia de escuchar su voz, sino más bien de cómo en esa falacia ella habló imprevisiblemente. De hecho y a pesar de los condicionamientos y limitaciones, Menchú siempre ha sostenido que en ese proyecto editorial ella contó la historia que quería contar y en la dosis adecuada ${ }^{6}$. Su iniciativa, por lo tanto, estaba en otro lugar y no en el afuera en el que inicialmente se colocó.

Las expectativas generadas a "ambos lados" de esta obra se han revelado distantes, menos tácitas en su pactos y más planificadas por las dos partes que la emprendieron: ¿hasta dónde la construcción literaria de una voz testimonial contenía implícitamente un contrato de conducta bilateral?, ¿hasta dónde

\footnotetext{
${ }^{6}$ Aunque las consideraciones sobre Me llamo Rigoberta Menchú... no han permanecido inalterables en el tiempo para su protagonista, Rigoberta Menchú dio cuenta de ellas en la entrevista realizada por Alice A. Brittin y Kneya C.Dworking (1993). Marc Zimmerman $(1999,502)$ también ha hecho referencia a esta cuestión a propósito de un intercambio personal con la propia Menchú.
} 
compromete prestar el material o facilitar su publicación?, ¿hasta dónde lleva este guión y sus ganancias simbólicas y pecuniarias?

Más allá de la agria polémica en torno a los derechos de autoría de Me llamo Rigoberta Menchú..., esta disputa añadida dirime con crudeza exacta y crematística la propiedad de "Rigoberta Menchú" como recurso: a quién pertenece esa creación y su personaje, a quién se debe su persona y con quién debe rendir cuentas ella misma. El sentido, la credibilidad y la rentabilidad se cruzan enrarecidos en este bestseller de la literatura testimonial.

\section{El objeto de estudio y los saberes en juego}

En el prólogo a Rigoberta Menchú y la historia de todos los guatemaltecos pobres ${ }^{7}$, David Stoll se preguntaba: “¿Qué tal si gran parte de la historia de Rigoberta no es verdadera?” para concluir "el dilema que me obligó a escribir este libro es la posibilidad de que un símbolo valioso también sea sumamente engañoso" (Stoll, 2002 [1999]: s.p). Dos cuestiones llaman la atención de estas declaraciones: la primera de ellas, la facilidad con la que Stoll neutraliza la verdad testimonial de Rigoberta Menchú, mediante la identificación exacta que establece entre su vida, lo que contó a Burgos y lo que finalmente quedó en el libro (de un solo trazo: "la historia de Rigoberta"); la segunda, entroncada con la anterior, se refiere a su valor añadido: "símbolo valioso" pero "sumamente engañoso". A la pérdida de densidad identitaria se superpone entonces la carga simbólica que la acompaña, que Stoll considera no sólo fraudulenta sino que, como detallaremos más adelante, personificaba el peligro más inmediato de los estudios de crítica testimonial y cultural en el campo académico estadounidense.

Sus acusaciones, ampliamente difundidas, partían de una investigación que mostraba inexactitudes en los acontecimientos narrados por Menchú además de incluir episodios en los que no estuvo presente o haber narrado en primera persona historias ajenas o situaciones de las que no fue, estrictamente, testigo ${ }^{8}$.

\footnotetext{
${ }^{7}$ El libro fue publicado originalmente en inglés por Westview Press (Boulder, Colorado, EE.UU) en 1999, pero existe una traducción digital al español con fecha de 2002, a cargo de Sara Martínez Juan y autorizada por D. Stoll que se puede consultar en la página web: http://www.nodulo.org/bib/stoll/rmg.htm. Las citas del mismo en el presente artículo remiten a esta fuente electrónica.

${ }^{8}$ A saber, el fallecimiento por desnutrición de uno de sus hermanos, las condiciones del asesinato de su otro hermano Patrocinio a manos del ejército, las circunstancias que rodearon la muerte de su padre en la embajada de España, su asistencia a un colegio de monjas belgas o su participación en los cortes de café, entre otros.
} 
A pesar de que estos detalles fueron los que trascendieron a la prensa nacional estadounidense del momento ${ }^{9}$, en realidad no constituían el centro de sus argumentaciones en contra de la capacidad representativa del testimonio de Menchú y su validez como documento de estudio en las universidades norteamericanas. Sin embargo, la sospecha que desde entonces acompañaría a la Premio Nobel de la Paz $^{10}$ (Rigoberta puede ser una mentirosa), le permitiría poner en duda no sólo la relación establecida entre movimiento guerrillero y comunidad indígena (un tema al que Stoll ya había dedicado investigaciones anteriores ${ }^{11}$ ) y la sobrevaloración de la misma, sino también las recientes transformaciones del campo curricular que colocaban al sujeto subalterno en una posición de privilegio y que anunciaban un posible desplazamiento de la autoridad del antropólogo y del etnógrafo tradicional:

La nueva ortodoxia parte de la premisa que las formas occidentales del conocimiento, como el enfoque empírico adoptado aquí, están fatalmente influenciadas por el racismo y por otras formas de dominación [...]. La nueva base de autoridad consiste en dejar que los subalternos hablen por sí mismos, repudiando cualquier indicio de complicidad con el sistema que los oprime y alineándose en relación con los teóricos de moda (Stoll, 2002 [1999]: s.p).

Las imputaciones, entonces, se dirigían en dos frentes: el primero tenía que ver con el cuestionamiento de determinados principios metodológicos -que recaían no sobre el trabajo de Burgos, sino sobre la figura de Rigoberta Menchú y la comunidad intelectual que se estaba haciendo cargo de la enseñanza, promoción y difusión del texto- , el lugar que determinados intelectuales querían ocupar en relación a conflictos "locales" complejos como el de Guatemala, en busca de "rebeldes en países lejanos, en los cuales los profesores” podían "proyectar sus fantasías de rebelión” (Stoll, 2002 [1999]: s.p.); el segundo radicaba en el cuestionamiento de la representatividad de Rigoberta Menchú respecto a la comunidad maya, en la medida en que para Stoll, ella representaba una facción ideológica relacionada

\footnotetext{
${ }^{9}$ La polémica pasó mucho más desapercibida en países europeos como España, quizá porque los Estudios Culturales siguen siendo un terreno poco arraigado en el ámbito crítico o, quizá porque, a diferencia del contexto estadounidense, esta polémica no suscitaba una reflexión sobre los proyectos curriculares universitarios. Lo cierto es que, con la excepción de unos breves artículos publicados en El País al mismo tiempo en que su grupo editorial publicaba Rigoberta Menchú, la nieta de los mayas (Aguilar, 1998), la polémica Stoll-Menchú no trascendió en el espacio académico y mediático del país.

${ }^{10}$ El sesgo con el que los medios de comunicación presentaron estos argumentos determinó que derivaran hacia las "verdades" y "mentiras" de Rigoberta Menchú y que una parte de la prensa pudiera cuestionar incluso su concesión del Nobel de la Paz (Rother, 2001 [1998]: 58), algo insólito en la larga tradición de estos premios y que no ha sido puesto en duda con otros personajes más cuestionables o de dudoso mérito como Henry Kissinger. La cuestión tuvo que ser zanjada finalmente por Geir Lundestad, director del Instituto Nobel de Noruega, aludiendo al hecho de que "todas las autobiografías se embellecen en mayor o menor medida" y el premio no fue concedido "exclusivamente basado en la autobiografía" (Rohter, 2001 [1998]: 60-61).

11 En concreto, su tesis doctoral publicada en 1993 con el título Between Two Armies in the Ixil Towns of Guatemala.
} 
con el movimiento revolucionario armado de Guatemala y su versión de los hechos estaba sesgada por sus intereses políticos ${ }^{12}$ :

La política exterior de Ronald Reagan (1981-1989) revivió la guerra fría a expensas de los centroamericanos y alimentó los criterios polarizados. La investigación académica en la región se politizó de tal manera que quienes se oponían a la política exterior de los EE.UU no creían que fuera necesario disculparse por estar 'comprometidos'. Lo que requería una disculpa y un profundo examen de conciencia era contradecir públicamente a la izquierda centroamericana y a sus partidarios norteamericanos (Stoll, 2002 [1999]: s.p).

De la cita se desprende cómo desde el cuestionamiento del discurso de Menchú y su visión de la insurgencia indígena, sus argumentos derivaban hacia el terreno político e ideológico, un espacio en el que Stoll acabó presentándose como mártir de una comunidad intelectual que lo denigraba por contrastar la versión de Menchú con la de otros informantes (igualmente subalternos y, por ello, igualmente autorizados según las corrientes postmodernas que consideraba en auge), como víctima de la autocensura ${ }^{13}$ por contradecir el discurso académico de la political correctness a favor de los movimientos revolucionarios de América Latina:

En el caso de Guatemala, yo no debía hablar de cómo los campesinos contribuyen a su pobreza al tener familias grandes o de cómo la guerrilla desencadenó los asesinatos políticos en algunos lugares o de la falta de comunicación entre la izquierda y las personas que quiere representar" (Stoll, 2002 [1999]: s.p).

Sin embargo, el campo crítico en el que Stoll se presentaba como un solitario y honesto investigador había emprendido con anterioridad una revisión sobre los alcances del testimonio que no sólo había trascendido los equívocos de su paradigma referencial y su dimensión representativa, sino que también había problematizado su vinculación en relación a ciertos procesos democratizadores o el lugar de la subalternidad como categoría de análisis para América Latina. En las fechas en que el antropólogo publica su libro, ya se contaba con las aportaciones de J. Beverley (1990, 1991), G. Yúdice (1991) o la

\footnotetext{
12 Otros autores pasaron entonces a señalar los lugares ideológicos desde los que David Stoll enunciaba sus propuestas. A propósito de esta cuestión J. Beverley señala: "La prueba de su falta de objetividad [del testimonio de Menchú] son las ausencias o tergiversaciones que [D. Stoll] encuentra en su testimonio, que, según Stoll, están relacionadas con la agenda ideológica que Menchú quiere promover. Esto implica que hay una posición objetiva, neutral, no-ideológica distinta de la posición 'comprometida' de Menchú, y que Stoll está en esa posición. Sin embargo, es evidente que Stoll también tiene una agenda política explícita” (Beverley, 2002: 11).

${ }^{13}$ En el capítulo 17, al hilo de las primeras polémicas surgidas con motivo de la presentación de algunas de sus investigaciones en entornos académicos, Stoll sostiene que se vio limitado a "discutir mis averiguaciones con los colegas, pero eludir su publicación” (Stoll, 2002 [1999]: s.p).
} 
recopilación editada por G. M. Gugelberger (1996) -por citar solo algunos ejemplos- a los que su estudio apenas muestra atención ${ }^{14}$.

Como hemos señalado, aunque, aparentemente, las acusaciones de Stoll remitían a la estricta veracidad de los hechos relatados por Menchú a Burgos, en términos de si la primera fue testigo directo o si pudo falsear, recrear o inventar algunos de los episodios narrados en el libro, sus implicaciones llegaron más lejos en tanto sus argumentos se prestaron a un recorte interesado en su difusión mediática, tanto como a un enmascaramiento de sus propios intereses.

En última instancia, la cuestión de fondo que realmente parecía preocupar a Stoll remitía sólo tangencialmente a Me llamo Rigoberta Menchú..., aunque como paradigma del género e icono de la causa solidaria, Menchú pasó a sintetizar buena parte de los debates que discutirían los alcances sociales del testimonio y la capacidad de la institución literaria y cultural para generar visiones desde o con el otro en la década siguiente ${ }^{15}$.

La incidencia de su libro pasó factura en el espacio crítico y sus forcejeos siguen vigentes. Por suerte o por desgracia, sus repercusiones no se pueden desdeñar como tampoco, en palabras de Zimmerman que “claramente, Stoll tenía sus propias intenciones; él deseaba quitar a Menchú de su pedestal y de ese modo hacer jugar para sus propias y muy diferentes ideas provenientes de sus entrevistas en el altiplano a finales de los ochenta" (Zimmerman, 2004: s.p.). Pero, sin necesidad de desvelar las ambiciones personales de Stoll -no es el único con deseos de figurar y de obtener réditos sobre su versión-, sin necesidad de descalificar enteramente su cuestionamiento y sin necesidad de favorecer una lectura ciega a favor o en contra, es preciso, como apuntó Zimmerman en su momento y como no fue bien entendido (Zimmerman, 2001/2002), pensar críticamente alrededor de esta intervención, para que los estudios culturales y postcoloniales puedan ser rearticulados como "un resultado positivo de esos debates” (Zimmerman, 2004: s.p.). Como el propio Gugelberger consideró, si el testimonio "no hizo necesariamente visible al subalterno, el testimonio ha ayudado a hacernos visibles a nosotros mismos" (Gugelberger, 1996: 3).

\footnotetext{
${ }^{14}$ A pesar de que, en un primer momento, la crítica no cuestionó la veracidad de los textos (en lo que a su dimensión histórica se refiere), la polémica se localiza ya en un artículo de 1982, donde E. Sklodowska señalaba la problemática relación historia/ ficción en el relato testimonial y, más tarde, Doris Sommer (1991) planteó las estrategias discursivas de Menchú como construcción retórica de su lugar de enunciación. El propio Stoll había intervenido en algunos encuentros académicos a principios de los años noventa e incluso le hizo llegar un manuscrito a J. Beverley sobre sus averiguaciones que aparece mencionado en la introducción de La voz del otro (1992).

15 En esta línea se mueven los principales trabajos que aparecieron desde finales de los ochenta y principios de los noventa: Yúdice (1991), Achugar (1989, 1992, 1997), Beverley (1989, 1992), Jara y Vidal (1986), Jameson (1992), etc.
} 


\section{Cuando los zulús tengan un Tolstoi...}

"Cuando los zulús tengan un Tolstoi..., nosotros lo leeremos”, así se refirió el novelista Saul Bellow en un periódico de Chicago a la transformación curricular que había comenzado en la Universidad de Stanford a propósito de la apertura del canon y el desplazamiento de ciertas lecturas tradicionales que respondían a un paradigma europeo, blanco y masculino. La misma carga simbólica se aplicaba a Me llamo Rigoberta Menchú... y su posterior concesión del Premio Nobel de la Paz a la que en la misma línea, Stoll se había referido como: “¿Rigoberta, qué?”.

Aseveraciones como estas colocaron el testimonio de Menchú más allá de su intrínseca problemática textual para convertirlo, anecdóticamente, en centro del conflicto ideológico de Estados Unidos en la era Reagan, conocido como The Culture Wars. Mary Louis Pratt (1999) ha documentado ampliamente este debate, pero resulta pertinente reproducir aquí sus bases por la incidencia que tendría alrededor de toda la polémica Stoll-Menchú y los efectos respecto a la construcción de los espacios de la crítica en la misma.

Nuevamente, la validez de ciertos presupuestos de partida en esta diatriba valió a ciertos sectores intelectuales fuertemente reaccionarios como estandarte para discutir, ya no el testimonio de Menchú, sino el sistema académico estadounidense: “en un nivel, lo que [estaba] en juego en EE. UU no [era] Rigoberta Menchú, ni Guatemala ni el testimonio en sí, sino la autoridad académica propiamente dicha” (Pratt, 1999: 32). A su vez, conviene recordar, como sugiere Pratt, que lo que proyectó en el espacio norteamericano estuvo muy alejado de lo que se podía dilucidar en el guatemalteco o latinoamericano (Pratt, 1999: 25). La disociación de la crítica sobre el testimonio y sobre Menchú, más allá incluso del litigio como objeto de estudio, encauzaba en su nombre un debate público sobre temas que nada tenían que ver ni con el libro ni con ella.

La incorporación de alumnos chicanos, afroamericanos, asiático-americanos, mujeres, etc., unido a la generación de los hijos de los sesenta en el circuito académico produjo no sólo la diversificación del universo estudiantil, sino también la del profesorado y la apertura curricular en un momento en que la multiculturalidad se convirtió en eje de la nueva identidad norteamericana. En ese espacio "resultaba incongruente proponer a tal estudiantado que ese corpus de lecturas representara de alguna manera 'las 
raíces de su cultura' e imposible reproducir la impresión de una 'experiencia intelectual común' en un momento en que la gente estaba aprendiendo más bien sus diferencias” (Pratt, 1999: 27) ${ }^{16}$.

Ya antes de la publicación del libro de Stoll, la discusión se había iniciado con la aparición del libro de Denish D’Souza, Illiberal Education (1991), que dedicó un capítulo completo a la incorporación del testimonio de Menchú en estas nuevas corrientes de estudio. El problema de la representatividad se orientaba en un doble sentido al evaluar su potencial ilustrador en términos de "una indígena analfabeta ignorante de quien nadie puede aprender nada", además de su escasa legitimidad, por "no ser una indígena suficientemente típica como para representar una visión indígena del mundo” (Pratt, 1999: $30)$.

En cualquier caso, D’Souza consideraba la inclusión de Me llamo Rigoberta Menchú... como una de las indeseables consecuencias de la apertura curricular universitaria en los términos en que la Universidad de Stanford lo condujo. Sus méritos estaban asociados a su compromiso político y a su capacidad de satisfacer las nuevas exigencias de un sector de la academia y las reivindicaciones de sectores minoritarios, no a su propio testimonio:

Rigoberta no es una víctima común. Como Burgos-Debray sostiene, ha sufrido múltiples vectores de opresiones simultáneas. Rigoberta es 'una persona de color', y por ello, víctima de racismo. Es una mujer y por tanto víctima del sexismo. Vive en Sudamérica [sic] que es víctima del colonialismo europeo y norteamericano. Por si esto no fuera suficiente, es indígena, victimizada por la cultura latina en América Latina. La reivindicación de Rigoberta es que, como víctima consumada, está completamente identificada con las actuales corrientes de historia. Los estudiantes no leen sobre Rigoberta porque escribió un gran libro eterno, o porque protagonizó una gran hazaña, o inventó algo útil. Ella simplemente pareció estar en el lugar adecuado, en el momento adecuado" (D'Souza, 1991: 72).

En esta distinción, lo que pudiera reconocerse como un valor en la vida de Menchú se niega en la obra que la evoca, lo que retomando los términos de nuestro planteamiento, se traduce en un reconocimiento de Menchú como sujeto de sus acciones, pero una descalificación de las mismas cuando se traducen como objeto, al "elevarlas" en forma de libro, programa de estudios o agenda cultural. La disociación entre ética y estética valía como imputación de victimismo y oportunismo contra su persona y revertía en una contienda de autoridades, en términos muy similares a lo que Stoll propondría después.

\footnotetext{
${ }^{16}$ El corpus al que se refiere Pratt se corresponde con el listado de los clásicos que la materia de "Cultura Occidental” incluía en su programa, entre los que se encontraban La Biblia, Platón, Homero, San Agustín, Dante, Maquiavelo, Galileo, Voltaire, Marx y Engels, Freud o Darwin, entre otros. La diversificación e incorporación de lecturas como Pedro Páramo, Me llamo Rigoberta Menchú... o Los condenados de la tierra, en el programa de una universidades más prestigiosas de Estados Unidos fue decisiva en este debate público sobre el multiculturalismo.
} 
Defensores y ofensores tomaron posición en este torneo que, más allá de Rigoberta Menchú, sentaba las bases del lugar desde el que pensar el compromiso intelectual del Norte con el Sur y escindía a quienes veían en él la posibilidad de escapar a las redes de dominación cultural de los centros de poder desde los que producían sus trabajos ${ }^{17}$, de quienes miraban con sospecha el giro político que muchas de estas investigaciones estaban llevando a cabo y la presencia de minorías en las mismas.

Todavía en el año 2001, Arturo Arias editó The Rigoberta Menchú Controversy ${ }^{18}$, un texto que pretendía constituir una visión panorámica de estas diferencias. También J. Beverley, en el prólogo a la segunda edición de La voz del otro: testimonio, subalternidad y verdad narrativa (2002), comenzaba su intervención con una referencia al libro de Stoll y una cita que, de forma provocativa y algo demonizadora, sintetizaba las consecuencias que sus críticas habían tenido en el marco intelectual y en la configuración de espacios teóricos de análisis en la academia norteamericana. La cita da cuenta de la virulencia que había alcanzado la reyerta:

Los defensores de la esclavitud [en los Estados Unidos] escudriñaban los escritos de los esclavos fugitivos para encontrar errores -cualquier pretexto para negar las descripciones que los esclavos ofrecían de los abusos que sufrieron- y a veces alegaban que los autores verdaderos eran los abolicionistas, no los esclavos. (Henry Louis Gates citado por Beverley, 2002: 1).

John Beverley zanjaba de esta manera la controversia Stoll-Menchú reubicándola en lo que consideraba su verdadero trasfondo: el desafío del testimonio a la autoridad narrativa del letrado y la diferencia sustancial entre aquellos intelectuales dispuestos a reconocerle un valor cultural -como espacio para la articulación de nuevos proyectos nacionales más heterogéneos, democráticos e igualitarios (Beverley, 2002: 15)- y quienes se resistían a hacerlo. Sin embargo, la proyección mediática, crítica y mercantil de Rigoberta Menchú ni se agota ni se escribe exclusivamente en un debate que, a estas alturas, da la impresión de ser siempre el mismo; más bien parece que se diversifica, se transforma y localiza en numerosos puntos de fuga que rodean su figura, la atraviesan o la proyectan hacia los nuevos escenarios globales.

\footnotetext{
${ }^{17} \mathrm{O}$ también, como una forma de acercar problemáticas que podían traducirse en el reflejo de la situación multicultural y heterogénea del ámbito educativo estadounidense. En este sentido, el libro Teaching and Testimony. Rigoberta Menchú in the North American Classroom sintetizó algunas de las propuestas pedagógicas y experiencias docentes alrededor del testimonio de Menchú. Las distintas colaboraciones incluidas en el volumen sugieren la utilidad de la lectura y el trabajo con el testimonio de Rigoberta Menchú para recrear o enfrentar a los estudiantes con las desigualdades sociales de su propio contexto histórico y como una forma de sensibilización hacia los problemas nacionales y nacionales respecto a las minorías, los excluidos y la opresión.

${ }^{18}$ Como ya se mencionó, ese mismo año, apareció también Stoll-Mechú: la invención de la memoria, un libro de ensayos editado por Roberto Morales en el que se presentaban intervenciones de D. Stoll, E. Volek, E. Burgos y R. Morales en una línea similar a la de Stoll.
} 
Nuria Girona y Gema Palazón. Rigoberta Menchú...

\section{La polémica infinita}

En el año 2008 se reeditó el libro de Stoll sin ninguna modificación a excepción de un nuevo prólogo firmado por Elizabeth Burgos. En las páginas iniciales, la antropóloga recuerda su intervención en el debate anteriormente reseñado y cuánto había llovido desde aquella lejana tarde en la que se gestó

\section{Me llamo Rigoberta Menchú...:}

No es mi propósito desacreditar o rehabilitar a Rigoberta Menchú. Tampoco deseo entrar en polémicas. Pero jugué un determinado papel en el lanzamiento de su carrera y algunos académicos estadounidenses se han tomado la libertad de proyectar sus teorías sobre mi relación personal con ella. Por ello, he decido aceptar la oportunidad de prologar el libro de David Stoll (Burgos, 2008: IX).

Sin duda, es una oportunidad para lo que Burgos plantea como un desquite. A pesar de negar su intención de "entrar en polémicas", el lugar y el momento de estas declaraciones la colocan de lleno en ellas. La forma de referirse a su propio trabajo de mediación, ahora en términos de “papel” en el "lanzamiento" de la carrera de Menchú indica un cambio en sus posiciones y en la consideración de Rigoberta Menchú que ha dejado de ser, en sus observaciones, la indígena ingenua cuyo exotismo anacrónico y deslocalizado se paseaba en huipil por las calles de París.

Varias cuestiones alrededor de estas variaciones merecen ser retomadas para mostrar cómo la reformulación de Burgos ilustra de forma precisa la definitiva desavenencia entre Menchú tomada como objeto y Menchú como sujeto de sus propias acciones.

Sus primeras palabras en este prólogo evocan la legitimidad de aquel lugar de enunciación concedido por la publicación de su obra cuyo privilegio se le ha vuelto en contra. Quién mejor que ella para “teorizar” sobre Menchú (dada su "relación personal”) y continuar la larga nómina de publicaciones y artículos, dimes y diretes que rodean su figura. Pero también para rememorar, ahora que muchos parecen haberlo olvidado, que fue ella el detonante del testimonio sobre el que tanto se ha discutido y escrito.

Burgos escoge, en esta ocasión, situarse en un afuera de aquello que constituyó, durante años, el punto neurálgico de la disputa sobre la veracidad de la obra para inscribirse en una tradición más amplia (la testimonial y la de la relación de la disciplina antropológica con la misma), más allá del libro que la asoció irremediablemente a ella. Así traza su propia genealogía profesional -que la vincula, como hace notar, a la disciplina de la que Stoll también forma parte- desde sus propias experiencias en Venezuela (donde de niña, escuchó relatos sobre el horror y la tortura de la mano de algunos familiares) y de sus años en Cuba, donde destaca que vivió allí mientras Miguel Barnet escribía y publicaba Biografía de un cimarrón (otro de los textos canónicos de la crítica testimonial) (Burgos, 2008: X). De este modo rescata 
un interés anterior y vocacional como puntos de anclaje a partir de los cuales emprendió su famoso proyecto editorial.

Dentro de esta genealogía y desde su propia experiencia (es decir, en el valor testimonial de la misma), Burgos contextualiza el origen de sus entrevistas con Menchú como un encuentro de carácter político-solidario para dar a conocer las atrocidades que se estaban cometiendo con las comunidades indígenas en Guatemala y despertar la solidaridad internacional: "Muchas veces, Marie y yo habíamos discutido la necesidad de una voz legitimada desde el interior de Guatemala, de alguien profundamente involucrado en la lucha allí, para dar mayor resonancia a nuestra campaña de solidaridad en Francia" (Burgos, 2008: X).

Unas páginas después, la antropóloga enuncia lo que podríamos considerar un indicio de "la gran decepción” sobre Rigoberta y le recrimina no haber vuelto a su comunidad indígena y trabajar desde allí:

Quizás fue un error no volver al lugar en el que había nacido, trabajar conjuntamente con aquellos a los que había dicho pertenecer. En lugar de ello, creó una fundación que en primer lugar llevaba el nombre de su padre, Vicente Menchú, y esto tenía un sentido simbólico profundo por su peso histórico. Al reemplazar su nombre con el suyo propio, [Menchú] pareció convertir la fundación en una mera proyección de sí misma. (Burgos, 2008: XVII).

Así se evidencia lo que Burgos considera una incoherencia del objeto que ella misma había contribuido a crear y que exigía, implícitamente, una praxis y una subjetividad que su mediación daba por supuesta. De paso, su crítica se extiende también a la comunidad académica de la que se ha sentido desplazada a propósito de las polémicas respecto al libro de la discordia ${ }^{19}$ : "Los teóricos subalternistas no están satisfechos con el hecho de que el testimonio se ha convertido en un género amplio y apreciado en América Latina. Además, pretenden que reemplace la literatura latinoamericana” (Burgos, 2008: $\mathrm{XVI})$.

Varias incongruencias asoman al respecto y no solo que Burgos se asegurara la difusión de sus declaraciones justamente en la reedición de un libro que podía considerarse difamatorio de su labor para mostrar, quizás, que su profesionalidad no quedaba empañada por las acusaciones de Stoll. Lo más llamativo radica en que, tal y como lo plantea Burgos, podríamos considerar que "usar" a Rigoberta Menchú tuvo sentido mientras servía a los objetivos programáticos de la facción guerrillera con la que ambas colaboraban, pero sólo si esta quedaba reducida al espacio de lo local, sólo si seguía siendo un sujeto subalterno sin autonomía real más allá de la concedida por quienes les "permitían hablar". La lucha por la representación a la que Jean Franco se refirió para caracterizar el testimonio se convirtió en

${ }^{19}$ Dos aspectos enmarcan esta cuestión: de un lado, la factura que su participación y desencuentros con Menchú le habían ocasionado en el espacio crítico estadounidense; de otro, su ruptura tanto con el régimen castrista como con la EGP en Guatemala durante los ochenta. 
una batalla ganada por Menchú, pero entonces, su valor de cambio como subalterna se esfumó al mismo tiempo que su proyección pública se volvía discutible, cuestionable. El discurso del sujeto subalterno (Menchú) se habría convertido en hegemónico sobre el que sujetos centrales (Stoll o Burgos, entre otros) se podían presentar victimizados.

El cisma de esta situación lo constituye el Premio Nobel que Menchú recibió (tras una campaña nacional e internacional) en 1992: "De repente, comprendí que mi papel a la hora de producir el libro una década antes se había convertido en un bochorno político; me había convertido en persona non grata" (Burgos, 2008: XI).

Paradójicamente, la justificación de Burgos corrobora el argumento con el que Stoll había pretendido deslegitimar el valor testimonial de Me llamo Rigoberta Menchú..., al considerar que la relación de Menchú con el EGP y su participación política sesgaban su visión de la lucha armada de Guatemala. El autor pone en duda su veracidad en el mismo texto que Burgos prologa y en el que ella misma reconoce, veinte años después, valores de propaganda política: "El testimonio era una forma de integrar a las clases más bajas, las cuales proveerían de combatientes a la guerrilla, como propaganda de guerra” (Burgos, 2008: XII). Cabe preguntarse, sin embargo, qué peso específico puede tener esta afirmación cuando el testimonio de Menchú no comenzó a circular en el interior de Guatemala hasta 1986 (Arias, 2001: 7) y nunca gozó de la resonancia que obtuvo internacionalmente ${ }^{20}$.

De este modo Burgos respalda las teorías que Stoll sostuvo en su investigación, en un gesto en el que sitúa el origen de Me llamo Rigoberta Menchú... al margen de su protagonista, como una iniciativa que no pasó por el deseo de Menchú sino más bien como una colaboración oportuna en su trayectoria profesional, en un proceso que le concedía a Menchú poder sobre aquello que contar o guardar como secreto, incluida la responsabilidad por la veracidad de lo narrado -de la que el trabajo antropológico parece eximirse- pero ningún control sobre lo enunciado más allá del momento en que fue relatado.

De lo anterior se desprende que la concesión del Premio Nobel (1992) imprimió un punto de inflexión en la difusión internacional de Menchú y un giro en sus actuaciones. Porque hasta aquí hemos visto cómo, convertida en objeto de estudio, desplazó los debates sobre los usos críticos del discurso del subalterno y de su consideración teórica como tal hasta combates "metacríticos" y enfrentamientos ideológicos revestidos de política y ética (paladines frente a fustigadores, izquierda y derecha, compromiso político y disciplina de estudio, etc.).

\footnotetext{
${ }^{20}$ Quizá el libro fue concebido como un proyecto de carácter político y es cierto que Elizabeth Burgos sometió al juicio de la EGP su manuscrito final antes de la publicación. Sin embargo, parece más probable que los intereses estuvieran dirigidos hacia las redes de solidaridad internacional y no hacia la captación de nuevos combatientes indígenas en un entorno en el que la inmensa mayoría eran analfabetos y en el que el texto enfrentaría serios problemas para su circulación.
} 
En la medida en que el discurso teórico giraba sobre sí mismo y se interrogaba entonces sobre los límites de su saber (Beverley, 1999), Rigoberta Menchú se convertía en personaje público al hacerse cargo no sólo de su propia imagen, sino también al empezar a hacer uso del lugar que las coyunturas académicas y la visibilidad mundial de su figura le proporcionaban. Esta transformación de Rigoberta Menchú / objeto en Rigoberta Menchú / sujeto incluía su participación en los acuerdos de Paz para Guatemala, el cambio de nombre de la Fundación Vicente Menchú (1993) por el de Fundación Rigoberta Menchú Tum (1995), su nombramiento como embajadora de buena voluntad de la ONU (1993), el Premio Príncipe de Asturias de Cooperación Internacional (1998), múltiples Doctorados Honoris Causa (en Centroamérica, Europa y Estados Unidos) y su participación en volúmenes de cuentos y poemas. Fue en estas coordenadas que se volvieron a desatar numerosas intervenciones, juicios de valor y análisis en los que resuena el citado reproche de Burgos: "fue un error no volver al lugar en el que había nacido, trabajar conjuntamente con aquellos a los que había dicho pertenecer”.

Menchú después del Nobel ya no es subalterna, ni indígena, ni representantiva de los indígenas ni puede ocupar un espacio más allá del reducto de lo local del que, aparentemente, nunca debería haber salido pero que constituyó la base del proyecto para editar Me llamo Rigoberta Menchú...

Lo que Sklodowska había recogido como "el síndrome de la Malinche" en su proceso de "ladinización” (Sklodowska, 1992: 125) o lo que ningún malvado acierto de D’Souza o David Stoll supo prever, terminó transformando el "símbolo valioso" en "sumamente engañoso". En este nuevo cruce de inculpaciones no se sabe qué molesta más: haber sido engañados (imprevisible logro de la subalterna avezada) o las formas de ese engaño (el pago con la misma moneda).

\section{¿Quién burló a quién?}

Hay que preocuparse menos de cómo nos apropiamos de Menchú y entender y apreciar más cómo ella se apropia de nosotros para sus propósitos.

John Beverley

Tampoco las reflexiones más benévolas procedentes de la teoría postcolonial y sus discusiones sobre si puede hablar o no el subalterno supieron escuchar lo que Menchú había dicho en su primera intervención con Burgos ni atinar en las que le seguirían, tomada a menudo como el personaje ausente de persona.

La decepción o el asombro que despertaron sus iniciativas descubren hasta qué punto su fetichización como objeto no incluía al sujeto que le dio pie y menos un simulacro por su parte. Al parecer, el monopolio del poder-de-representación no solo exigía un control de los medios discursivos 
en la que esta se daba a conocer o la subordinación como objeto de saber, sino que fijaba y sancionaba tanto su identidad como su futura rentabilidad. La contradicción de la que partió el proyecto de Me llamo Rigoberta Menchú... lo minaba desde dentro: su valor de resistencia a la captura institucional le fue otorgado por la misma institución que gestionaba internamente ese valor, según advirtió crudamente Nelly Richard, aquel "poder fáctico de la Internacional académica, cuya serie coordinada de programas de estudio, líneas editoriales y sistemas de becas fija y sanciona tanto la vigencia teórica como la remunerabilidad de las investigaciones en curso de acuerdo a valores de exportación” (Richard, 1997: $348)$.

De qué otra manera pueden entenderse las discusiones críticas sobre la representatividad, la identidad y la praxis de Menchú sino como tasas de apropiación en las que el plus otorgado debía corresponderse con el plus recibido. Pero algo falló en esta inversión que las ganancias no regresaban ni en la forma prevista ni revertían en quien las aguardaba.

El premio a la subalternidad presuponía una identidad y una representación reducida a una formulación monocorde, de acuerdo a una coordenada que debía cumplirse en términos reivindicativos y a ser posible, desde una posición de debilidad. De forma transparente, también las polémicas reproducidas en los apartados anteriores dan cuenta de que las nociones bipolarizadas de "resistencia cultural" o "alteridad" no admiten cruces ni hibridaciones con los espacios hegemónicos ni calculados mimetismos.

Distingamos: Rigoberta Menchú dio nombre al libro que la presentó como protagonista -incluso como testigo- y la hizo hablar como "Rigoberta Menchú” - ¿de por vida, funcional y ontológicamente? El fraude se le atribuye cuando se confiesa autora de sí misma y cuando se conoce el "uso" que de ella hizo en ese momento; cuando lo que dijo no solo era lo que se esperaba oír de ella, sino lo que ella misma quiso decir. Es decir, cuando se desvela que la pose no fue tan forzada:

La construcción de Menchú fue hecha para concitar solidaridad, fue hecha para otros. Esos otros son los que ahora reclaman ser espejos mejor pulidos que los demás y, como el lobo de Caperucita, parecieran pelear por el privilegio de haber trabajado "para reflejarte mejor", olvidando que la imagen que el espejo devuelve es la pose que el sujeto adoptó frente a él para construirse como objeto de conocimiento para sí y para otros (Morales: 185).

Quizás, quien muy pronto reparó en estos espejismos sobre las “poses” hegemónicas de Menchú y sobre cómo tomaba prestado el lenguaje y ciertas estrategias dominantes, fue Doris Sommer en su conocido artículo "Sin secretos" (1991), aunque posiblemente el tiempo se ha encargado de conferirle nuevos sentidos a su análisis.

Las proyecciones que conlleva el hábito de lectura de atribuir sinceridad a un escritor o considerar inviolable la verdad de una obra, inclusive a pesar de la evidencia de su construcción textual, literalmente, 
advertía: "no son nada generosas" (Sommer, 1991: 135), lo que hoy puede leerse en toda su magnitud y no solo con respecto a Me llamo Rigoberta Menchú..., por favorecer "una apropiación no problematizada" o ignorar "la insistencia del texto en el valor político de mantenernos a una distancia" (Sommer, 1991: 135).

Aunque Sommer también anunció la "cosificación del sujeto latinoamericano" y diagnosticó condescendencia, paternalismo, desdén y alabanza al respecto (Sommer, 1991: 151), su propuesta no escapaba ni de asignarle un "uso" a Menchú ni de caer en la impenetrabilidad de sus designios, que tanta resistencia le conferían. Si en aquel momento se miraba en su espejo para "incitarnos a aprender estrategias políticas de aquéllos que consideramos otros” (Sommer, 1991: 151) y su silencio devolvía "nuestras ansias de saber" (Sommer, 1991: 137), su estrategia se estimaba defensiva, necesaria como política de preservación cultural y recordatorio constante de la diferencia.

Pero quizá la insistencia de Menchú en esa distancia apuntaba en otra dirección -si es cierto que dijo lo que quería decir-, con lo que probablemente Sommer ya no podría mantener la declaración de que “personalmente, prefiero pensar que sus secretos son más “literario' que 'reales”” (Sommer, 1991: 139) porque se desvelaron tan literales como literarios.

No solo funcionaron como una estrategia retórica de seducción para interesarnos en su pasado ancestral o recordar nuestra incapacidad como lectores, sino como una promesa de posteriores entregas, a expensas de completar la información nunca servida. Quizás uno de los motivos, no el único, para publicar posteriormente otro libro de memorias: Rigoberta: la nieta de los mayas (1998 en España) y lucir habilidades narrativas que invitaban a ensayar la modalidad lírica en los poemas incluidos en Trenzando el futuro, unos años antes ${ }^{21}$. Las publicaciones, invitaciones y conferencias tanto en seminarios como en foros internacionales se multiplicaron después de la concesión del Nobel pero, de hecho, ya antes Menchú había transitado como icono subalterno, feminista o transculturado.

Los reproches y reclamos en torno a Me llamo Rigoberta Menchú... pregonan los intereses acerca de otro de los secretos convenidamente custodiado: que la obra, al fin y al cabo, respondía a un minucioso y controlado proceso de manufactura para impulsarla como bien de consumo y que su eficacia

\footnotetext{
${ }^{21}$ Sobre la "carrera literaria" de Menchú, su relación con otros escritores guatemaltecos y su articulación de un nuevo espacio discursivo en los 90, véase Zimmerman (2006).
} 
conciliadora la opacó como producto de mercado ${ }^{22}$. Que Menchú tomó parte activa de este proceso, más allá de proporcionar la "materia prima" y dirigir su autorrepresentación ha sido señalado por Zimmerman:

Si finalmente acordó dictar su historia de forma más completa, ella sabía que estaba produciendo una mercancía, pero usó la misma lógica correcta que había empleado cuando decidió favorecer la adopción del castellano como lingua franca para los grupos indígenas de su país (Zimmerman, 2006 [1999]: 173).

Pero más allá de retomar las estrategias "ladinas" de Menchú, desde el momento en que su visibilidad corría pareja a la de su mercantilización también se ahuecaba. ¿Cabrá recordar, con Martín Barbero, que "el mercado no puede crear vínculos societales" por más eficaz que sea su simulacro?:

No puede sedimentar tradiciones ya que todo lo que produce "se evapora en el aire" dada su tendencia estructural a una obsolescencia acelerada y generalizada, no sólo de las cosas sino también de las ideas y las instituciones. El mercado no puede crear vínculos societales, verdaderos lazos entre sujetos, pues estos se constituyen en conflictivos procesos de comunicación de sentido, y el mercado opera anónimamente mediante lógicas de valor que implican intercambios puramente formales, asociaciones y promesas evanescentes que sólo engendran satisfacciones o frustraciones pero nunca sentido. El mercado no puede en últimas engendrar innovación social pues ésta presupone diferencias y solidaridades no funcionales, además de resistencias y subversiones (Barbero, 1998: XV-XVI).

\footnotetext{
${ }^{22}$ Reproducimos la extensa cita de Arturo Arias al respecto para salvar de ella no tanto las pugnas personales sobre la obra, sino este calculado proceso de elaboración: "Burgos-Debray estaba buscando a alguien con sus características para hacer una entrevista, y Taracena concertó un encuentro entre Menchú Tum y Burgos-Debray, una etnógrafa de origen venezolano, muy bien conectada con casas editoriales en Francia a través de su ex-marido, Régis Debray, entonces ministro en la administración Mitterrand. Finalmente, se tomó la decisión de transcribir la historia de Menchú Tum, un proceso que tuvo lugar durante las primeras semanas de 1982 en la casa de Burgos-Debray. Muchos aspectos de este proceso mantiene puntos contradictorios sobre ese día. Arturo Tracena reivindica que participó en parte de la entrevista él mismo, algo que BurgosDebray, niega. David Stoll está de acuerdo con Burgos-Debray en este punto [...] Arturo Taracena reivindica que la mayor parte del trabajo de transcripción fue llevado a cabo por Paquita Rivas, una joven mujer cubana que era la secretaria de Gonzalo Arroyo, un jesuita chileno exiliado en Francia que conducía el Centro Católico para la Ayuda de América Latina. Taracena también reivindica que él mismo hizo la mayor parte de la edición. Stoll, por otra parte, aprueba/coincide con la revindicación de Burgos-Debray de que fue ella la única editora. Stoll también concuerda con la posición de Burgos-Debray respecto a que el manuscrito fue revisado por Rolando Morán, comandante en jefe del EGP, mientras Taracena insiste en que fue Gustavo Meoño, anterior presidente de la Fundación Menchú, quien leyó y sugirió pequeñas modificaciones para proteger la identidad de los miembros del EGP, pero que el EGP no estuvo realmente interesado en el proyecto. En lo que todos concuerdan es en que el manuscrito editado fue presentado por Burgos-Debray al premio de Casa de las Américas, donde ganó el Premio Testimonio en 1983. Sin embargo, los desacuerdos se reanudaron inmediatamente después de eso. Menchú Tum reivindica que, al no recibir ningún dinero del premio, se dio cuenta de que Burgos-Debray había registrado todos los copyrights en su propio nombre. Stoll concuerda con Burgos-Debray en que pagó los royalties /derechos a la organización que Menchú Tum y Taracena indicaron y que tiene en posesión las facturas de esas cantidades de dinero. Sea lo que sea lo que pasó, fue el prestigioso premio internacional el que marcó el inicio de la proyección pública de Menchú Tum. Sin embargo, debido a la situación política en el interior de Guatemala, permaneció desconocida en su país de nacimiento" (Arias, 2001: 8).
} 
Si Menchú abrió toda una línea productiva en el debate académico sobre "el fetichismo de la subalternidad", su valor añadido como bien simbólico, "el fetichismo de la mercancía" con la que se comercializó ha dejado sin palabras respecto a cómo afrontar no si los subalternos pueden hablar (Zimmerman, 2006 [1999] o si lo que ocurre es que aunque lo hagan no poseen autoridad cultural (Beverley, 2002), sino si pueden permanecer como tal después de un Premio Nobel y numerosos doctorados honoris causa; o cuando "Rigoberta la indígena, Rigoberta la mujer, Rigoberta la víctima subalterna, Rigoberta la activista de derechos humanos” (Zimmerman, 2006 [1999]: 173) dan a luz a Rigoberta empresaria, Rigoberta activista civil, Rigoberta candidata presidencial.

Más allá del calco del personaje que ella misma había creado o de la habilidad que ha mostrado para manejarlo y trascenderlo, sus actuaciones más recientes también proyectan una de las tensiones más acuciantes de nuestra época: la interacción de la cultura con la dinámica transnacional de los mercados, así como la configuración de nuevas comunidades y demandas políticas que trascienden la soberanía estatal.

De su colaboración con el Comité de Unidad Campesina (CUC) o la Unión Revolucionaria Nacional Guatemalteca (UNRG), su apoyo a Arzú o su propia candidatura a las formas más recientes de un liderazgo desterritorializado, la figura de Menchú actualiza -no sabemos, nuevamente, si como efecto o como agente de ella-, las transformaciones de las condiciones de existencia y operación de las culturas nacionales y locales, que como ella misma, se reelaboran y se enriquecen tanto como se disuelven y se pierden. La diversidad que encarna es desde donde resiste pero a la vez desde donde se impone - ¿como negociación que cruza de otra manera estrategias hegemónicas/globales con dominadas/locales?-. Hasta dónde los valores ganados (circulación, movilidad, diversidad, innovación) contra las fronteras o las identidades estables funcionen como política de la diferencia está por ver.

Aleccionados, el desengaño quizá no deba formularse en los términos con los que Zimmerman redimensionaba la discusión académica: "subalternabilidad no es garantía de honestidad o virtud. De hecho, la subalternabilidad puede evitar tales cualidades, así como los subalternos libran sus guerras contra-hegemónicas con armas débiles o fuertes. Los subalternos algunas veces mienten al decir su verdad" (Zimmerman, 2004: s.p.), sino en el desconcierto cauteloso que relata al referir uno de sus últimos encuentros con Menchú, mientras ella iba caminando por el lobby del Hotel Saint Bonaventure de Los Ángeles, donde no parecía perdida lo más mínimo y llevaba en la mano un nuevo manuscrito de sus poesías:

Al comentarle que yo quería hablar con ella, me respondió que no tenía tiempo. No lo tenía porque se iba a una reunión de un grupo de estudios subalternos sobre la construcción lacaniana del sujeto colectivo, las micro-narrativas y los movimientos en 
Nuria Girona y Gema Palazón. Rigoberta Menchú...

busca de una democracia radical. Llevaba una camiseta de Stanford (o de la Université de Montreal) bajo su huipil (Zimmerman, 1999: 517). 
Nuria Girona y Gema Palazón. Rigoberta Menchú...

\section{Bibliografía}

Aceituno, Luis. "Rigoberta Menchú: libro y vida. Arturo Taracena rompe el silencio". Casa de las Américas, año XXXIX, 214 (1999): 129-135.

Achugar, Hugo (1989). "Notas sobre el discurso testimonial latinoamericano". (Chang-Rodríguez, Raquel, eda.). La historia en la literatura iberoamericana. Nueva York: Ediciones del Norte: 279-294.

Achugar, Hugo. "Leones, cazadores e historiadores. A propósito de las políticas de la memoria y del conocimiento". Revista Iberoamericana LXIII, 180 (1997): 379-387.

Achugar, Hugo. "Historias paralelas/historias ejemplares: la historia y la voz del otro". (Beverley, John; Achugar, Hugo, eds.). Revista de Crítica literaria latinoamericana, 36 (Monográfico La voz del otro: testimonio, subalternidad y verdad narrativa). Latinoamericana Editores, 1992. 41-70.

Arias, Arturo (2001a). "Rigoberta Menchú's History within the Guatemalan Context”. (Arias, Arturo, ed.). The Rigoberta Menchú Controversy. Minneapolis: Minnesota UP: 3-28.

Arias, Arturo (ed.) (2001b). The Rigoberta Menchú Controversy. Minneapolis: Minnesota UP.

Arias, Arturo. “¿Hacia dónde nos dirigimos desde aquí? Consecuencias teóricas de la actitud de Stoll para los estudios culturales centroamericanos". Istmo. Revista virtual de estudios literarios y culturales centroamericanos, 3 (2001c)

Beverley, John (1989). Del Lazarillo al sandinismo: estudios sobre la función ideológica de la literatura española e hispanoamericana. Minneapolis: Institute for the Study of Ideologies and Literature y Prisma Institute.

Beverley, John; Zimmerman, Marc (1990). Literature and Politics in the Central American Revolutions. Austin: University of Texas Press.

Beverley, John. “Introducción”. (Beverely, John; Achugar, Hugo, eds.). La voz del otro: testimonio, subalternidad y verdad arrativa. Monográfico especial de la Revista de crítica literaria latinoamericana, vol. 18, 36. Lima y Pittsburg: Latinoamericana Editores: 7-20.

Beverley, John (1999). Subalternity and representation: Arguments in Cultural Theory. Durham: Duke University Press.

Beverley, John; Achugar, Hugo (eds) (2002). La voz del otro: testimonio, subalterniad y verdad narrativa. Guatemala: Universidad Rafael Landívar. 
Nuria Girona y Gema Palazón. Rigoberta Menchúw..

Beverley, John. "The Neoconservative Turn in Latin American Literary and Cultural Criticism". Journal of Latin American Cultural Studies, 17, 1 (2008): 65-83.

Brittin, Alice A., y Kenya C. Dworking. "Rigoberta Menchú: 'los indígenas no nos quedamos como bichos aislados, inmunes, desde hace 500 años. No, nosotros hemos sido protagonistas de la historia”. Nuevo Texto Crítico, vol. VI, 11 (1993): 207-222.

Burgos, Elizabeth (1997) [1992]. Me llamo Rigoberta Menchú y así me nació la conciencia. Barcelona: Seix Barral.

Burgos, Elizabeth (2008). "Foreword to the 2008 Edition: How I Became Persona Non Grata". David Stoll, Rigoberta Menchú and the Story of All Poor Guatemalans. Colorado: Westview Press: IX-XVII.

Carey-Webb, Allen; Benz, Sthephen (eds.) (1996). Teaching and Testimony. Rigoberta Menchú and the North American Classroom. New York: State University of New York Press.

D’Souza, Dinesh (1991). Illiberal Education: The Politics of Race and Sex on Campus. New York: Free Press.

Franco, Jean (1992). "Si me permiten hablar: la lucha por el poder interpretativo". (Beverley, John; Achugar, Hugo, eds.). La voz del otro: testimonio, subalternidad y verdad narrativa. Monográfico especial de la Revista de Crítica Literaria Latinoamericana, vol. 18, 36. Lima y Pittsburgh: Latinoamericana editores: 109-116.

Gugelberger, George M.,(ed.) (1996). The Real Thing: Testimonial Discourse and Latin America. Durham y Londres: Duke University Press.

Gugelberger, George M. (1996). "Introduction: Institucionalization of Transgression: Testimonial Discourse and Beyond”. En Gugelberger, George M., (editor). The Real Thing: Testimonial Discourse and Latin America. Durham y Londres: Duke University Press: 1-19.

Jameson, Fredric (1992). "De la sustitución de importaciones literarias y culturales en el tercer mundo: el caso del testimonio". (Beverley, John; Achugar, Hugo, eds.). La voz del otro: testimonio, subalternidad y verdad narrativa. Monográfico especial de la Revista de Crítica Literaria Latinoamericana, vol. 18, 36. Lima y Pittsburgh: Latinoamericana editores: 117-134.

Jara, René; Vidal, Hernán (eds.) (1986). Testimonio y literatura. Minneapolis: Society for the Study of Contemporary Hispanic and Lusophone Revolutionary Literatures. 
Martín Barbero, Jesús (1998). De los medios a las mediaciones. Comunicación, cultura y hegemonía. Santa Fé de Bogotá: Andrés Bello.

Menchú, Rigoberta (1998). Rigoberta Menchú, la nieta de los mayas. Madrid: Aguilar.

Morales, Mario Roberto (coord.) (2001). Stoll-Menchú: la invenciónd e la memoria. Guatemala: Consucultura.

Morales, Mario Roberto. “Sobre la ley del silencio y la censura académica”. La insignia (2003).

Morales, Mario Roberto. "Serving Two Masters, Or, Breathing Artificial Life Into A Lifeless Debate (A Reply to John Beverley". Journal of Latin American Cultural Studies, 17:1 (2008): 85-93.

Pratt, Mary Louise. "Lucha-libros. Rigoberta Menchú y sus críticos en el contexto norteamericano”. Nueva Sociedad, 162 (1999): 24-39.

Richard, Nelly. "Intersectando a Latinoamérica con el latinoamericanismo". Revista Iberoamericana, 180 (1997): 345-361. Disponible online [consultado el 20 de abril de 2009]: $<>$.

Rohter, Larry (2001) [1998]. “Tarnished Laureate”. (Arias, Arturo. ed.). The Rigoberta Menchú Controversy. Minneapolis: Minnesota UP: 58-65.

Sklodowska, Elzbieta. "La forma testimonial y la novelística de Miguel Barnet". Revista Ineramericana 12, 3 (1982): 375-384.

Sklodowska, Elzbieta (1992). Testimonio hispanoamericano, historia, teoría, poética. Nueva York: Peter Lang.

Sommer, Doris. "Rigoberta's Secrets". Latin American Perspectives. Voices of the Voiceless in Testimonial Literature, Part I. Núm. 70. Vol. 18, 3 (1991): 32-50.

Stoll, David (1993). Between Two Armies in the Ixil Towns in Guatemala. New York: Columbia University Press.

Stoll, David (1999). Rigoberta Menchú and the Story of All Poor Guatemalans. Colorado: Westview Press.

Stoll, David (2002). Rigoberta Menchú y la historia de todos los guatemaltecos pobres. Sara Martínez Juan, traductora.

Yúdice, George. "Testimonio and Postmodernism". Latin American Perspectives Voices of the Voiceless in Testimonial Literature 18, 3, (1991): 15-31. 
Zimmerman, Marc (1995). Literature and Resistance in Guatemala. Textual Modes and Cultural Politics from El señor presidente to Rigoberta Menchú. Estados Unidos: Ohio University Press.

Zimmerman, Marc. "Rigoberta Menchú después del Nobel: de la narrativa militante a la lucha postmoderna”. Revista Canadiense de Estudios Hispánicos XXIII, 3 (1999): 499-519.

Zimmerman, Marc (2001/2002). “Rigoberta Menchú, David Stoll, Subaltern Narrative and Testimonial Truth: A Personal Testimony”. Boland, Roy C; Roque Baldovinos, Ricardo (eds.). From War to Peace / De la guerra a la paz: Perspectives on Modern Central American Literaturel Perspectivas sobre la literatura centroamericana moderna. Antípodas: Monographic Journal of Hispanic and Galician Studies. Australia: La Trobe University: 119-142.

Zimmerman, Marc. “Rigoberta Menchú, David Stoll, narrativa subalterna y la verdad testimonial: una perspectiva personal". Istmo. Revista virtual de estudios literarios y culturales centroamericanos, 8 (2004).

Zimmerman, Marc. Literatura y testimonio en Centroamérica: posiciones postinsurgentes. Houston: LACASA, Universidad Rafael Landívar, 2006. 